\title{
PREVALÊNCIA DE DEPRESSÃO E DEMÊNCIA EM ADULTOS E IDOSOS
}

\section{ATIVOS}

Gabriele da Graça Botesini, Universidade de Passo Fundo, botesini.gabriele@gmail.com;

Daniela Bertol Graeff, Universidade de Passo Fundo, danibertol@upf.br; Marilene Rodrigues Portella, Universidade de Passo Fundo, portella@upf.br; Bernadete Maria Dalmolin, Universidade de Passo Fundo, berna@upf.com.br; Helenice Moura Scortegagna, Universidade de Passo Fundo helecine@upf.br; Ana Luisa Sant'Anna Alves, Universidade de Passo Fundo, alves.als@upf.br

\section{RESUMO}

Introdução: Com a tendência global ao envelhecimento humano, o Brasil trará consigo o aumento da prevalência de doenças crônico degenerativas, dentre elas: demência e depressão, consequentes desse processo multifatorial que resultam na diminuição da qualidade de vida e funcionalidade do idoso. Objetivo: Verificar a ocorrência de depressão e demência em adultos e idosos participantes de um Centro de Referência e Atenção ao Idoso. Métodos: Estudo de caráter observacional do tipo transversal, com indivíduos frequentadores de um Centro de Referência e Atenção ao Idoso. As variáveis utilizadas foram obtidas por meio de questionário estruturado contendo e instrumentos validados de livre acesso: Escala de Depressão Geriátrica, Mini-Exame do Estado Mental, Teste do Desenho do Relógio, o Teste de Fluência Verbal Semântica dos Animais e o Alzheimer's Disease Assessment Scale. Resultados: A amostra foi de 167 participantes. As prevalências de depressão e demência foram $6 \%(\mathrm{n}=10)$ e 12,6\% $(\mathrm{n}=21)$, respectivamente. Para o desfecho demência, comparando os participantes classificados com e sem cognição prejudicada, respectivamente, a idade média foi 71,9 $( \pm 9,52)$ vs. $65,9( \pm 7,61)$ anos; a média dos anos de estudo foi $7,5( \pm 4,12)$ vs. $12,3( \pm 4,47)$; e o tempo que viveu no meio rural antes de ir para o meio urbano foi $24,10( \pm 8,45)$ vs. $16,80( \pm 12,44)$ anos. Dentre os indivíduos classificados como cognição preservada, a classe econômica que se mostrou mais prevalente foi a A. Conclusão: Diante dos achados, observa-se baixa prevalência de depressão e demência, podendo esta ser influenciada por atividades físicas, sociais, culturais e educacionais realizadas no Centro de Referência.

Palavras Chave: Demência; Depressão; Envelhecimento.

Agradecimentos: O presente trabalho foi realizado com apoio da Coordenação de Aperfeiçoamento de Pessoal de Nível Superior - Brasil (CAPES) - código de financiamento 001. 